\title{
Long-Term Thermal Regimes of Subgrade under a Drainage Channel in High-Altitudinal Permafrost Environment
}

\author{
Hong Yu $\mathbb{D}^{1,2,3}$ Hongwu Han $\mathbb{D}^{4},{ }^{4}$ Wei Ma $\mathbb{D}^{2,3}$ Zekun Ding $\mathbb{D}^{2,3}$ and Ling Chen $\mathbb{D}^{2,3}$ \\ ${ }^{1}$ School of Civil Engineering, Lanzhou University of Technology, Lanzhou 730050, China \\ ${ }^{2}$ State Key Laboratory of Frozen Soil Engineering, Northwest Institute of Eco-Environment and Resources, \\ Chinese Academy of Sciences, Lanzhou 730000, China \\ ${ }^{3}$ University of Chinese Academy of Science, Beijing 100049, China \\ ${ }^{4}$ Qinghai Water Resources and Hydropower Engineering Bureau Co. Ltd., Xining 810001, China
}

Correspondence should be addressed to Wei Ma; mawei@lzb.ac.cn

Received 4 January 2021; Revised 23 January 2021; Accepted 2 February 2021; Published 12 February 2021

Academic Editor: Ying-hao Huang

Copyright (c) 2021 Hong Yu et al. This is an open access article distributed under the Creative Commons Attribution License, which permits unrestricted use, distribution, and reproduction in any medium, provided the original work is properly cited.

In permafrost regions, construction of a channel involves a large amount of excavation activities and changes to surface water body, which can exert great impacts on the thermal regimes of permafrost underlying. In this paper, a coupled mathematical model of heat and moisture transfer was constructed for freeze-thaw soils to investigate the long-term thermal regimes of subgrade beneath a drainage channel built on the Qinghai-Tibet Plateau. Based on the numerical simulations, the thermal regimes of the subgrade both in warm and cold seasons were analyzed within a period of 50 years, as well as the impact of the widths of the channel. The results showed that the channel excavation and flowing water within could lead to a significant underlying permafrost degradation. During the first 30 years, the permafrost beneath the channel mainly experienced a rapid downward degradation. After that, the lateral thermal erosion of the flowing water led to a rapid permafrost degradation beneath the slope of the channel. In cold seasons, the shallow ground beneath the channel would not refreeze due to the flowing water and the thaw bulb actually expanded throughout the year. For the channel with a bottom width of $15 \mathrm{~m}$, the thaw bulb beneath the channel could expand laterally to the natural ground about $10 \mathrm{~m}$ far away from the slope shoulder of channel till the 50th year. With different widths, the long-term thermal regimes of the subgrade beneath the channels differed considerably and the maximum difference was at the slope toe of the embankment. With the numerical simulated results, it is recommended that a channel built on permafrost should be wide-and-shallow rather than narrow-and-deep if conditions permit.

\section{Introduction}

Permafrost is defined as ground (soil or rock including ice) with a temperature at or below $0^{\circ} \mathrm{C}$ for at least two consecutive years $[1,2]$. A quarter of the Northern Hemisphere and $17 \%$ of the exposed land surface of earth are underlain by permafrost [3]. The distribution of permafrost on earth can be of altitudinal and latitudinal character [4]. In China, the permafrost area accounts for $22 \%$ of the total land area, which is mainly distributed on the Qinghai-Tibet Plateau (QTP), the Northeastern China, and the high mountain areas in the Northwestern China. With an average elevation of more than $4000 \mathrm{~m}$, the QTP has the largest distribution of altitudinal permafrost on earth [5]. Compared with latitudinal permafrost in the Northern America and Siberia, the permafrost on the QTP is characterized with high temperatures and thermal unstable, thus being more sensitive to climatic changes and human activities [6-8].

The QTP is also known as the Asian Water Tower. It is one of the three major distribution areas of lakes in China, and its lake area accounts for more than $50 \%$ of the total in China $[9,10]$. In the context of global warming, the climate warming and wetting on the QTP was significant during the past decades, which led to significant changes in lake number and area [11-14]. The recent estimations showed that, since the mid-1990s, the area, level, and volume of lakes on the QTP showed a continuous increase $[15,16]$. In a study 
by Liu et al. [17], a rapid expansion since 2000 was observed for lakes in the endorheic basin on the QTP, particularly in the Hoh Xil region with a continuous permafrost distribution. The rapid expansion of lakes could cause flood disasters, which may exert significant threatens to the production and living of local communities, as well as major engineering infrastructures nearby [18-20].

In 2011, the Zonag Lake in the central of the Hoh Xil regions burst suddenly, which was an extreme case of lake evolution on the QTP. After the outburst, a deep and wide gully developed at the breaking point and the flood entered the downstream lakes including the Kusai Lake, Haiding Nor Lake, and Yanhu Lake. At present, the four lakes are already connected together, and the first three ones lost their storage functions, making the Yanhu Lake become a tailend-lake [21-24]. From 2011 to 2019, the surface area of the Zonag Lake decreased from 269 to $150 \mathrm{~km}^{2}$, while the surface area of Yanhu Lake increased by almost 3 times from 73 to $209 \mathrm{~km}^{2}[5,25]$. Considering the rapid changes, some researchers conducted predictions and concluded that an overflow would occur to the Yanhu Lake in a minimum of one to two years [21]. At about $10 \mathrm{~km}$ downstream the Yanhu Lake, there are the Qinghai-Tibet Railway, QinghaiTibet Highway, Qinghai-Tibet Power Transmission Line, Golmud-Lhasa Oil Pipeline, as well as several communication cables. It is well-known that all of them are of great importance for social and economic ties between the Tibet Autonomous Region and the inner China [26-28]. If the Yanhu Lake burst in an uncontrollable condition, these major linear infrastructures would be in danger and even be destroyed by the outburst flood.

To prevent this projected flood disaster, a large-scale drainage project was conducted in 2019 between the potential breaking point of the Yanhu Lake and the Qingshui River at the downstream $[9,29]$. When serving as subgrade of man-made infrastructure, the physical and mechanical properties of permafrost are closely related to its thermal regimes [30-33]. Meanwhile, along with seasonal freezing and thawing in the active layer, significant (differential) frost heave and thaw subsidence would occur at the ground surface, which can cause series of damages to structures built upon [34]. Thus, the thermal regime of permafrost is a key variable that determines the bearing capacity and deformation of foundations and the long-term stability and integrity of the structures upon [35-38]. With regard to evolution of permafrost thermal regimes beneath hydraulic structures, the related research studies were scarce as there has been almost no large-scale hydraulic engineering conducted in continuous permafrost regions. In related fields, research studies on thermal interactions between thermokarst lake and underlying permafrost were conducted both in latitudinal and altitudinal permafrost environments. In 1978, a large tundra lake was drained to study the aggradation of permafrost into newly exposed lake-bottom sediments, and the active-layer thickness, snow depth, minimum soil temperatures, near-surface ground ice, soil heave, and permafrost temperatures had been measured for over 20 years [39]. Lin et al. [40] conducted filed observations on water and ground temperatures beneath and around a $2 \mathrm{~m}$ deep thermokarst lake on the QTP and found that the mean annual ground temperatures beneath the thermokarst lake were more $5^{\circ} \mathrm{C}$ higher than those in the surrounding terrain at the same depths. In a study by Niu et al. [41], characteristics of about 250 thermokarst lakes on the QTP were investigated and their influences on permafrost were evaluated based on field measurements in ground temperatures around a lake in the Beiluhe Basin. Through using numerical methods, Wen et al. [42] and Ling and Zhang [43] simulated the temporal and spatial variation of ground temperature and talik thickness beneath an expanding thermokarst lake on the QTP and the Alakan Arctic, respectively. In a study by Wen et al. [42], the lake was assumed to expand linearly with time both in radius and depth, while in a study by Ling and Zhang [43], the lake was assumed to expand linearly with time only in radius. Li et al. [44] conducted a moisture-heat coupled numerical simulation to investigate the permafrost degradation beneath a thermokarst pond with consideration of climate warming. Compared with thermokarst lakes, however, the thermal impact of a drainage channel to underlying permafrost may be more significant and complex due to the excavation of the channel and the running water within the channel. With regard to channels built in cold regions, $\mathrm{Li}$ et al. [45] established a moisture-heat-mechanic couple mathematic model and investigated the freeze-thaw influence on the channel using numerical simulations. Considering the effects of the seepage water, Zhang et al. [46, 47] investigated the thermal regimes of the permafrost beneath the dike with various antiseepage measures.

In this paper, the drainage channel of the Yanhu Lake was taken as an example and the thermal interactions among the drainage channel, the drainage water body, and the underlying permafrost subgrade were investigated through field observations and numerical simulations. With the Harlan model and Richard equation, a coupled mathematic model for heat and moisture transfer in freezing-thawing soils was established. Then, a numerical model was constructed based on the engineering geotechnical investigation conducted in the field and the dimensions of the drainage channel. The numerical model was validated with field observations carried out at the drainage channel. Then, the long-term evolution of thermal regimes of permafrost beneath the drainage with three bottom widths was investigated after a validation through using numerical simulations. It is hoped that the results of this study can provide scientific references for predicting and warning of the safe operation of the drainage channel.

\section{Mathematical Model and Governing Equations}

2.1. Liquid Water Flows. Without considering the effects of water vapor, the equivalent volume of water content $\theta$ in freeze-thaw soil based on the law of mass conservation can be expressed as follows:

$$
\frac{\partial \theta}{\partial t}=\frac{\partial \theta_{u}}{\partial t}+\frac{\rho_{i}}{\rho_{w}} \frac{\partial \theta_{i}}{\partial t}=\nabla\left(q_{l h}\right)
$$


where $\theta$ is the equivalent volume of water content $\left(\mathrm{m}^{3} \cdot \mathrm{m}^{-3}\right)$; $\theta_{u}$ is the volume of unfrozen water content $\left(\mathrm{m}^{3} \cdot \mathrm{m}^{-3}\right) ; \theta_{i}$ is the volume of ice content $\left(\mathrm{m}^{3} \cdot \mathrm{m}^{-3}\right) ; \rho_{i}$ is the density of ice $\left(\mathrm{kg} \cdot \mathrm{m}^{-3}\right) ; \rho_{w}$ is the density of water $\left(\mathrm{kg} \cdot \mathrm{m}^{-3}\right) ; t$ is the time; and $q_{l h}$ is the liquid water flux density which can represent liquid flows due to a pressure head gradient $\left(\mathrm{m} \cdot \mathrm{s}^{-1}\right)$.

The migration of liquid water under potential gradient in frozen soil is similar to that in unfrozen unsaturated soil based on the Harlan model and can be described by Richard equation $[48,49]$. Then, it is mainly influenced by the factors including water potential gradient and hydraulic conductivity of soils. The values of water potential gradient and hydraulic conductivity in unfrozen and frozen soils differ considerably, while the regulation of water migration can still be assumed to Darcy's law [50]. Only considering the potential gradient, the flux density of liquid water can be expressed as follows [51, 52]:

$$
q_{l h}=-K_{l h} \nabla(h+y),
$$

where $y$ is the vertical coordinate $(\mathrm{m}) ; h$ is the pressure head (m); and $K_{l h}$ is the water conductivity coefficient of liquid water under the action of soil-water potential gradient $\left(\mathrm{m} \cdot \mathrm{s}^{-1}\right)$. Then, considering the equivalent volume water content $\theta$ as a dependent variable, the mass conservation equation of liquid water in unfrozen and frozen soils can be written as follows [53]:

$$
\frac{\partial \theta}{\partial t}=\nabla \cdot\left[K_{l h} \nabla(h+y)\right] .
$$

The relationship between the amount of water and energy in the soil can be reflected by soil-water characteristic curve (SWCC). Then, SWCC also can represent the relationship between matric, volume water content, and saturation in frozen and unfrozen soils [52]. In this study, the van Genuchten model and Mualem model are adopted to describe the hydraulic properties of unsaturated freeze-thaw soil $[53,54]$. The hydraulic properties can be written as follows:

$$
\begin{aligned}
h & =\frac{-\left(S_{e}^{1 /-m}-1\right)^{1 / n}}{\alpha}, \\
S_{e} & =\frac{\theta_{l}-\theta_{r}}{\theta_{s}-\theta_{r}}= \begin{cases}\frac{1}{\left[1+|\alpha h|^{n}\right]^{m}}, & h<0, \\
1, & h \geq 0,\end{cases} \\
K & = \begin{cases}K_{s} S_{e}^{l}\left[1-\left(1-S_{e}^{1 / m}\right)^{m}\right]^{2}, & h<0, \\
K_{s}, & h \geq 0,\end{cases}
\end{aligned}
$$

where $S_{e}$ is the effective saturation; $K_{s}$ is the saturation water conductivity coefficient $\left(\mathrm{m} \cdot \mathrm{s}^{-1}\right) ; \theta_{l}, \theta_{s}$, and $\theta_{r}$ are liquid water content, saturated liquid water content, and residual water content $\left(\mathrm{m}^{3} \cdot \mathrm{m}^{-3}\right) ; \alpha$ is the derivative of the soil intake value $\left(\mathrm{m}^{-1}\right) ; m=1-1 / n$; and $n$ and $l$ are experience parameters, and Mualem suggested that $l$ could be determined as 0.5 [54].

2.2. Heat Transfer. Compared with the heat conduction with phase change of ice to water, the energy released by the heat convection was very small and could be neglected during the heat transfer analysis of freeze-thaw soil [55-57]. Then, the governing equations of heat transfer in freeze-thaw soil can be written as follows [49]:

$$
C_{m} \frac{\partial T}{\partial t}=\frac{\partial}{\partial x}\left(\lambda_{m} \frac{\partial T}{\partial x}\right)+\frac{\partial}{\partial y}\left(\lambda_{m} \frac{\partial T}{\partial y}\right)
$$

where $C_{m}$ is the equivalent volume heat capacity and $\lambda_{m}$ is the equivalent thermal conductivity. According to the method of sensible heat capacity, equivalent volume heat capacity $C_{m}$ and equivalent thermal conductivity $\lambda_{m}$ in freeze-thaw soils can be written as follows $[55,58]$ :

$$
\begin{gathered}
C_{m}= \begin{cases}C_{f}, & T<T_{f}-\Delta T, \\
\frac{C_{u}+C_{f}}{2}+\frac{L_{s}}{2 \Delta T}, & T_{f}-\Delta T \leq T \leq T_{f}+\Delta T, \\
C_{u}, & T>T_{f}+\Delta T,\end{cases} \\
\lambda_{m}= \begin{cases}\lambda_{f}, & T<T_{f}-\Delta T, \\
\frac{\lambda_{u}-\lambda_{f}}{2}\left[T-\left(T_{m}-\Delta T\right)\right]+\lambda_{f}, & T_{f}-\Delta T \leq T \leq T_{f}+\Delta T, \\
\lambda_{u}, & T>T_{f}+\Delta T,\end{cases}
\end{gathered}
$$

where $T_{f} \pm \Delta T$ is the temperature range of phase change; $C_{u}$ and $\lambda_{u}$ are the volume heat capacity and thermal conductivity of unfrozen soil; $C_{f}$ and $\lambda_{f}$ are the volume heat capacity and thermal conductivity of frozen soil; and $L_{s}$ is the latent heat of phase change in per unit volume. While the temperature ranges of phase change in different soil are difficult to gain, the heat transfer equation adopted in this study is written as follows [49]: 


$$
C \frac{\partial T}{\partial t}=\frac{\partial}{\partial x}\left(\lambda \frac{\partial T}{\partial x}\right)+\frac{\partial}{\partial y}\left(\lambda \frac{\partial T}{\partial y}\right)+L \frac{\partial \theta_{i}}{\partial t} \rho_{i}
$$

where $C$ is the volume heat capacity; $\lambda$ is the thermal conductivity; and $L$ is the latent heat of freezing of liquid water (approximately $3.34 \times 10^{5} \mathrm{~J} \cdot \mathrm{kg}^{-1}$ ).

After soil freezing, not all liquid water can be transferred to solid ice. The rest of liquid water is called as unfrozen water. Then, the unfrozen water content is related to factors including the temperature, pressure, water salinity, mineralogy, soil specific surface area, and soil surface chemistry [59-62]. Based on previous work and related theories, the empirical expression as follows is used to determine the maximum unfrozen water content in the freezing process $[49,50,52]$ :

$$
\theta_{u \max }=a(T-273.15)^{-b}
$$

where $a$ and $b$ are parameters related to the soil properties. The volume liquid water content can be determined by temperature and equivalent volume $[50,52]$ :

$$
\theta_{l}= \begin{cases}\theta, & \text { others, } \\ \theta_{u \max }, & T<T_{f} \text { and } \theta>\theta_{u \max },\end{cases}
$$

where $T_{f}$ is the freezing point of saturated soil $\left(0^{\circ} \mathrm{C}\right)$. Previous studies showed that the freezing point of soil is not a fixed value, and the ice grows only when the water content exceeds $\theta_{u \max }[63]$.

\section{A Drainage Channel Built in High-Altitude Permafrost Environment}

3.1. Study Area and Drainage Channel. In this study, the drainage channel built for Yanhu Lake, in the Hoh Xil region on the QTP, was taken as an example. In the area, the elevation ranges from 4460 to $4500 \mathrm{~m}$ a.s.l. The meteorological data were collected from the $\mathrm{Wu}$ Daoliang weather station, which is about $70 \mathrm{~km}$ far away from the channel. The collected data showed that, in the period from 1965 to 2019, the main annual air temperature ranged from -6.5 to $3.7^{\circ} \mathrm{C}$ and the main annual precipitation ranged from 136 to $480 \mathrm{~mm}$. Since the 1980s, the climate warming and wetting at the region was significant.

A standard whether station was set up at the channel in 2020. Figure 1 shows the observed air temperatures during the monitoring period from 24 May to 10 November in 2020. In the period, the maximum air temperature reached to $12^{\circ} \mathrm{C}$, which appeared in mid-August. Combined with the collected air temperatures from the Wu Daoliang weather station, the air temperature at the projected area can be fitted using a sinusoidal function as follows:

$$
T_{o}=-3.02+11.6 \sin \left(\frac{2 \pi t}{365}+0.3\right)
$$

where $t$ is the time (d).

3.2. Ground Temperature Observation at the Channel. To observe thermal regimes of permafrost subgrade beneath the channel, three ground temperature boreholes including natural ground (NG), slope shoulder (SS), and slope toe (ST) of the channel were drilled after excavation of the channel (Figure 2). The three boreholes were $20 \mathrm{~m}$ in depth. Considering the symmetry of the channel, the three boreholes were all arranged at one side of the channel. Within each borehole, 32 ground temperature sensors were installed with a spacing of $0.5 \mathrm{~m}$ between $0-10 \mathrm{~m}$ depth and of $1 \mathrm{~m}$ below $10 \mathrm{~m}$ depth. The measurement range of the sensor is from -40 to $40^{\circ} \mathrm{C}$, with an accuracy of $\pm 0.05^{\circ} \mathrm{C}$. All the sensors were connected to a CR6 data collector, and the observation frequency of ground temperatures was 6 hours.

\section{Numerical Simulations and Results Analysis}

4.1. Computational Model. Previous studies showed that the boundary error would be less than $10 \%$ when the computational domain is 3-5 times of the equivalent diameter of the model [64]. In this study, the computational model was constructed based on the actual dimension of the channel. The depth of the channel was $4.7 \mathrm{~m}$, and the bottom width was set as $25 \mathrm{~m}$. The slope of the channel was released by $1: 3$. At present, the water depth within the channel was determined as $1 \mathrm{~m}$ throughout one year based on the field survey. The computation on thermal regimes of subgrade under the channel can be simplified as a 2D unsteady heat transfer problem.

According to the geological survey conducted before the drainage excavation, the soil strata can be simplified as sandy gravel, silty clay, and weathered mudstone from the surface down. The thermal and hydraulic parameters of the three soil layers are listed in Table 1, which were gained based on the borehole drillings and related laboratory tests $[34,49,50,52,65]$.

4.2. Boundary Conditions. According to the meteorological data from the $\mathrm{Wu}$ Daoliang weather station, the long-term air temperatures in the study area showed a linear increase with the rate of $0.33^{\circ} \mathrm{C} / 10 \mathrm{a}$. Then, based on the adherent layer theory [62], the upper boundaries of GF and FE were set as temperature boundary:

$$
T=-0.502+11.6 \sin \left(\frac{2 \pi t}{365}+0.3\right)+\frac{0.33 t}{3650},
$$

where $t$ is the time (d).

As an alternative to heat budget models, linear correlations between air and water temperatures during open water periods were studied widely in previous studies [66]. Based on the analysis of a stream's heat transport/budget equation, the air temperature shows a good linear relationship with water temperature. The relationship between the water temperature in the lake and the air temperature can be linearly fitted as follows:

$$
T_{w}(t)=A+B T_{a}(t)
$$

where $T_{w}(t)$ and $T_{a}(t)$ are the water temperature and the air temperature in the same time scale; $A$ and $B$ are constants; and $t$ is the time $(\mathrm{d})$. 


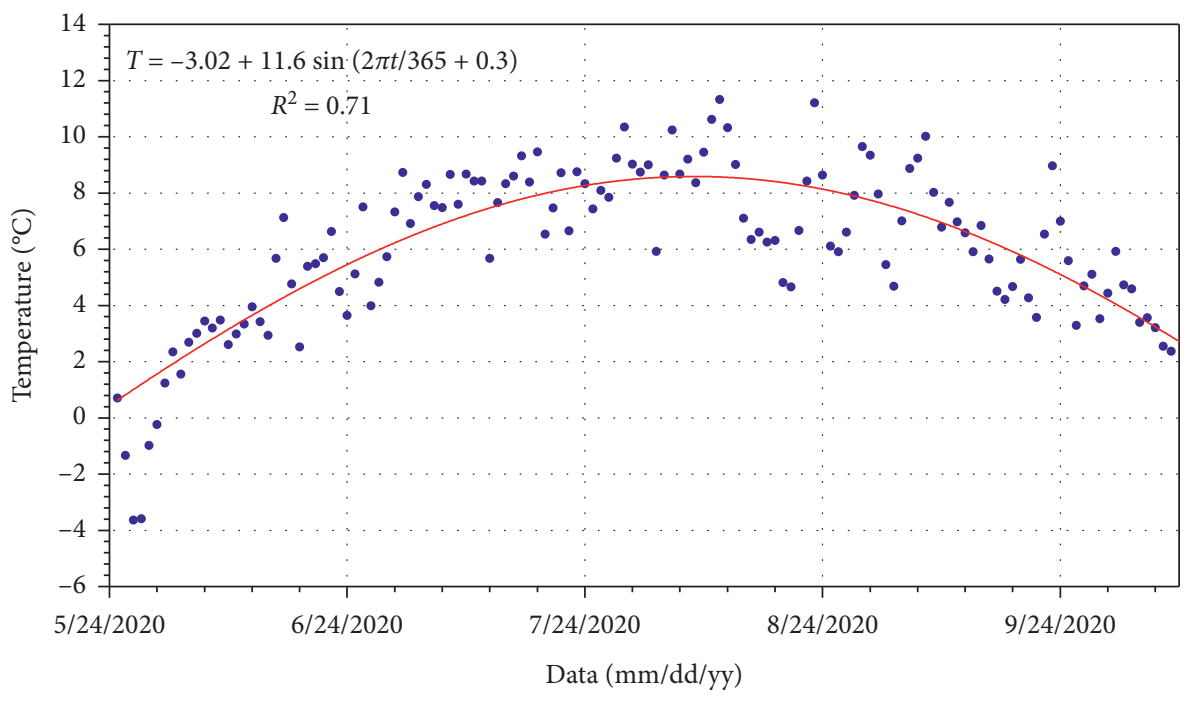

- Measured data

Fitted data

Figure 1: Observed air temperatures at the channel from May 24 to November 10, 2020.

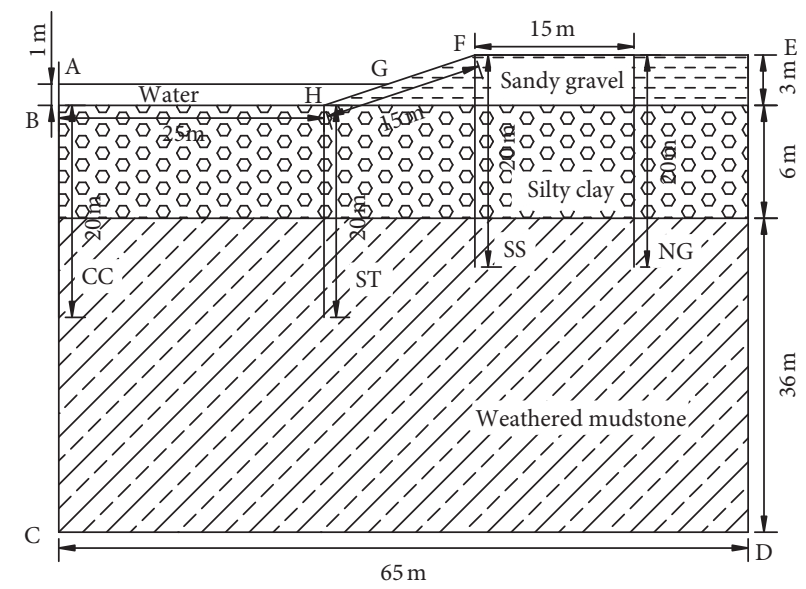

Figure 2: Ground temperature boreholes drilled at one side of the channel (unit: m).

TABLE 1: Thermal and hydraulic parameters of the three soil layers.

\begin{tabular}{|c|c|c|c|c|c|c|}
\hline Parameters & $\begin{array}{c}\lambda_{u} \\
\mathrm{~W} \cdot \mathrm{m}^{-1}{ }^{\circ} \mathrm{C}^{-1}\end{array}$ & $\begin{array}{c}\lambda_{f} \\
\mathrm{~W} \cdot \mathrm{m}^{-1}{ }^{\circ} \mathrm{C}^{-1}\end{array}$ & $\begin{array}{c}C_{u} \\
\mathrm{~J} \cdot \mathrm{m}^{-3 \circ} \mathrm{C}^{-1}\end{array}$ & $\begin{array}{c}C_{f} \\
\mathrm{~J} \cdot \mathrm{m}^{-3}{ }^{\circ} \mathrm{C}^{-1}\end{array}$ & $A$ & $B$ \\
\hline Sandy gravel & 1.91 & 2.61 & $2.41 \times 10^{6}$ & $1.86 \times 10^{6}$ & 10.67 & 0.57 \\
\hline Silty clay & 1.42 & 2.12 & $3.35 \times 10^{6}$ & $2.54 \times 10^{6}$ & 6.9 & 0.47 \\
\hline Mudstone & 1.47 & 1.82 & $2.09 \times 10^{6}$ & $1.84 \times 10^{6}$ & 9.3 & 0.52 \\
\hline Parameters & $\begin{array}{c}\alpha \\
m^{-1}\end{array}$ & $\theta_{r}$ & $\theta_{s}$ & $\begin{array}{c}K_{s} \\
\mathrm{~m} \cdot \mathrm{s}^{-1}\end{array}$ & $\begin{array}{c}\mathrm{P} \\
\mathrm{kg} \cdot \mathrm{m}^{-3}\end{array}$ & $\begin{array}{c}L_{s} \\
\mathrm{~J} \cdot \mathrm{m}^{-3}\end{array}$ \\
\hline Sandy gravel & 3.28 & 0.01 & 0.44 & $2.4 \times 10^{-7}$ & 1800 & $2.31 \times 10^{7}$ \\
\hline Silty clay & 2.6 & 0.02 & 0.35 & $3.3 \times 10^{-8}$ & 1600 & $6.51 \times 10^{7}$ \\
\hline Mudstone & 2.3 & 0.02 & 0.25 & $1.2 \times 10^{-8}$ & 1700 & $3.77 \times 10^{7}$ \\
\hline
\end{tabular}


According to the observed water temperatures (equation (15)) in lakes near the study area [40] and the air temperature showed as equation (16), the two constants of $A$ and $B$ in equation (14) used in this study were determined as follows:

$$
\begin{aligned}
& T_{w 1}=5.96+5 \sin \left(\frac{2 \pi t}{365}-0.65\right) \\
& T_{a 1}=-4.02+11.1 \sin \left(\frac{2 \pi t}{365}-8.18\right),
\end{aligned}
$$

where $t$ is the time (d).

Without considering the impacts of artificial heat inputs, ground water inputs, stream shading, and wind sheltering, the values of $A$ and $B$ in equation (14) in the same area have very slight differences [66]. Then, the water temperature in the channel can be written as equation (17). Thus, the boundary $\mathrm{BH}$ and $\mathrm{BG}$ were set as follows:

$$
T_{w}=4.72+5.21 \sin \left(\frac{2 \pi t}{365}+0.3\right)+\frac{0.15 t}{3650},
$$

where $t$ is the time (d).

The boundary condition at CD was set as heat flux with the value of $0.03 \mathrm{~W} / \mathrm{m}^{2}$, which was gained from the geothermal gradient within the ground temperature boreholes. The boundary of DE was thermal insulation boundary, and that of BC was the symmetry boundary. With the governing equations and boundary conditions above, the problem was solved numerically using the commercial software of COMSOL Multiphysics. The spatial and temporal discretization of governing equations was carried out by using the finite method. The simulation was conducted over a time period of 50 years before the drainage channel excavation to gain the initial temperature field. After the excavation, the boundary conditions were set as the ones described above.

4.3. Model Validation. A comparison between field observed and numerical simulated ground temperatures at ST on October 15 in the first year after the channel excavation was conducted to validate the numerical model and its parameterization (Figure 3). It can be found that the numerical simulated results agreed with the field observed well within the permafrost layer, including the depth of the permafrost table and the permafrost temperatures below. While in the active layer, there were some slight discrepancies between the numerical simulated and field observed ground temperatures. The discrepancies may relate to the simplification of the soil strata in the numerical simulation and the depth of the temperature sensors installed within the borehole. Overall, the numerical model and its parameterization in this study can be used to simulate the permafrost thermal regimes beneath the channel.

\section{Results and Analysis}

5.1. Long-Term Permafrost Thermal Regimes beneath the Channel in Warm Seasons. In the permafrost regions on the QTP, the maximum seasonal thaw depth generally occurs in
mid-October. In the following analysis, the time point was chose to investigate the long-term permafrost thermal regimes beneath the channel. For brevity, we only took the channel with the width of $15 \mathrm{~m}$ as an example.

Figure 4 shows the thermal regimes of subgrade beneath the channel on October 15 within the 50 years after the channel excavation. It can be seen that, due to combined thermal effects of the flowing water and climate warming, the permafrost beneath the channel degraded rapidly with time went on. While in the natural ground far away from the channel, the permafrost degraded slowly due to the climate warming effect. In the $5^{\text {th }}$ year, the maximum seasonal thaw depth at NG, ST, and centerline of the channel (CC) was 2.4, 9.2, and $10.5 \mathrm{~m}$, respectively. A thaw bulb developed beneath the channel due to the thermal effect of flow water. The permafrost temperatures beneath the channel also increased considerably comparing with those beneath the natural ground at the same depths. For example, at the depth of $10 \mathrm{~m}$, the permafrost temperatures under CC and NG were $0.14^{\circ} \mathrm{C}$ and $-0.45^{\circ} \mathrm{C}$, respectively, with a difference up to $0.6^{\circ} \mathrm{C}$. With increase in the operation time, the thaw bulb beneath the channel expanded rapidly in the vertical direction. In $10^{\text {th }}$ year after the channel excavation, the maximum seasonal thawing depth at CC and ST reached to 16.7 and $14.4 \mathrm{~m}$, respectively. Till the $30^{\text {th }}$ year, the permafrost beneath the channel degraded almost totally within the depth of $30 \mathrm{~m}$. After that, the later thermal erosion of the channel became considerable, and the permafrost beneath the channel slope degraded with the depth of $30 \mathrm{~m}$.

The above results showed that, during the first 30 years of the channel operation, the permafrost beneath the channel experienced a rapid downward degradation because of the significant thermal effect of the flowing water. Along with the rapid downward degradation of permafrost beneath the channel, a large lateral thermal gradient developed beneath the slope of the channel. This significant thermal gradient would cause uneven deformations of the slope and even slumps or collapse because of the temperature dependence of mechanical properties of frozen soils. Thus, how to ensure the slope stability of the channel is a great challenge in permafrost environment.

5.2. Long-Term Permafrost Thermal Regimes beneath the Channel in Cold Seasons. In mid-April, the active layer on the QTP generally refreezes completely. In order to investigate the thermal regimes of subgrade beneath the channel in cold seasons, ground temperature distributions within the subgrade on April 15 within the 50 years after the channel excavation were analyzed in this section.

Figure 5 shows the thermal regimes of subgrade beneath the channel on April 15 within the 50 years after the channel excavation. The shallow ground far away from the slope shoulder of the channel refrozen totally in cold seasons. While, beneath the channel, the thaw bulb beneath the channel did not freeze due to the flowing water. Compared with the last warm season in the same year (Figure 4), the thaw bulb still expanded in the following cold seasons. In the $5^{\text {th }}$ year, the thaw bulb mainly exited vertically beneath the 


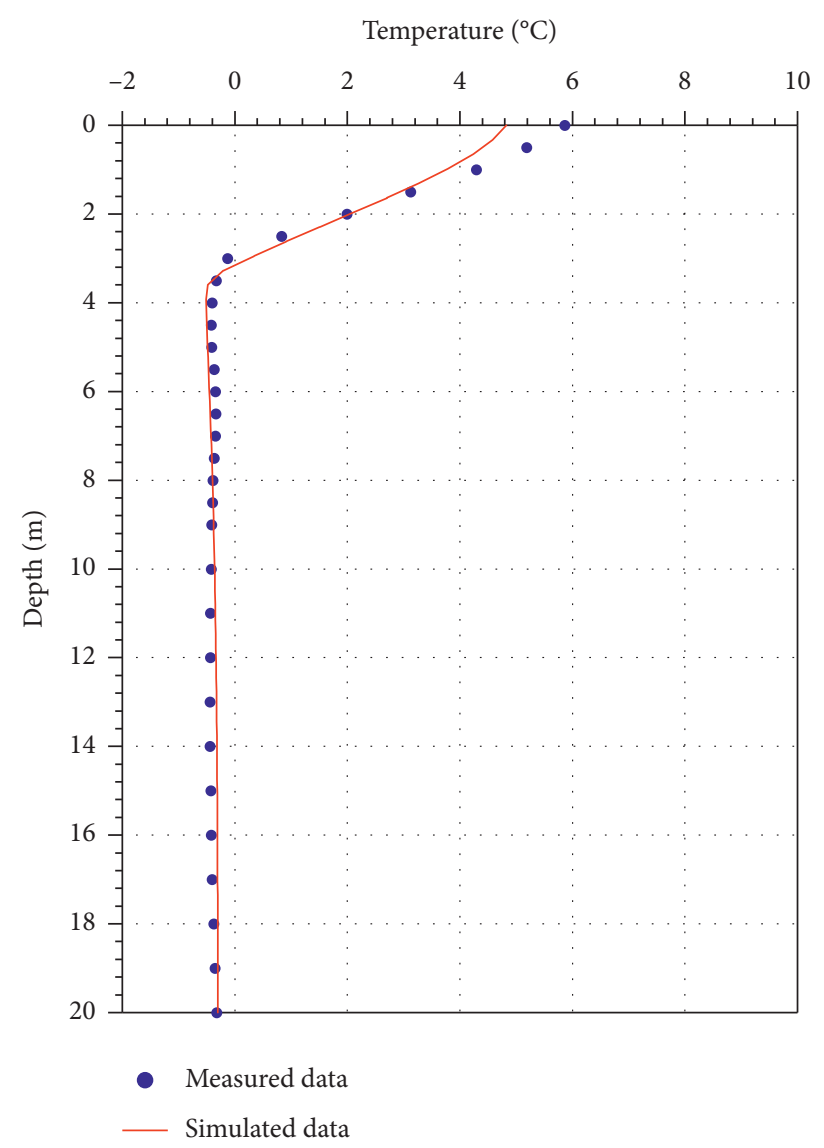

FIGURE 3: Field observed and numerical simulated ground temperatures vs depth at ST on October $15,1^{\text {st }}$ year after the excavation of the channel.

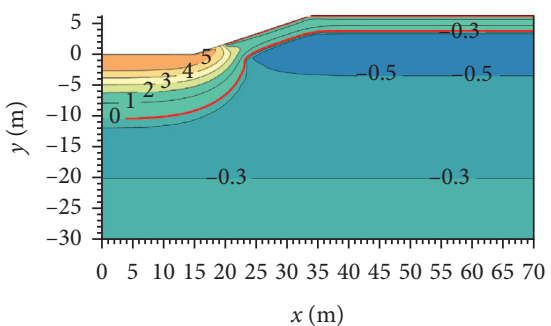

(a)

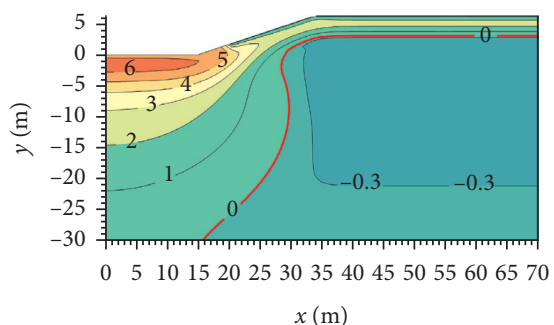

(d)

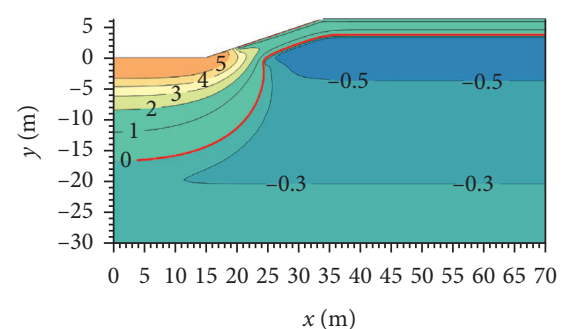

(b)

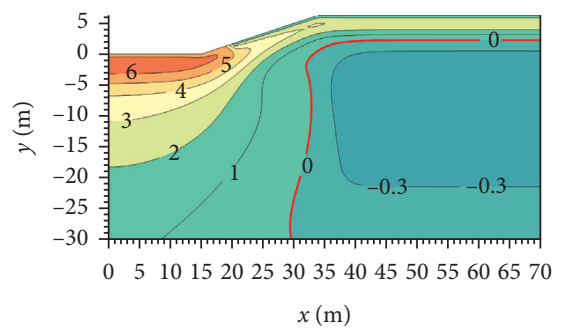

(e)

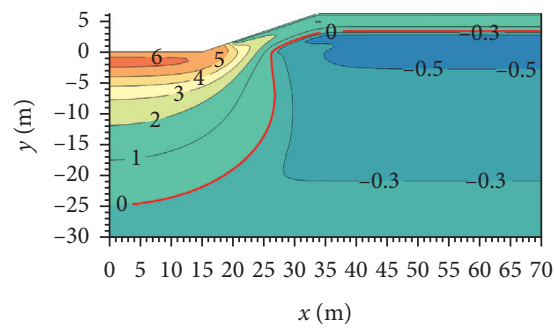

(c)

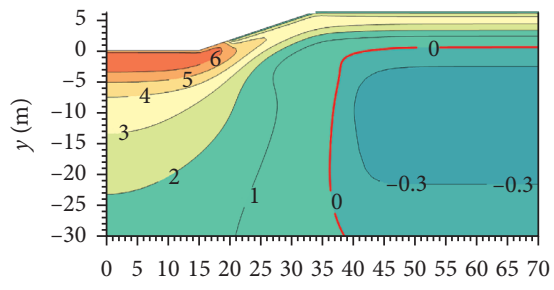

$x(\mathrm{~m})$

(f)

Figure 4: Thermal regimes of subgrade beneath the channel on October 15 after 5 (a), 10 (b), 20 (c), 30 (d), 40 (e), and 50 (f) years of the channel excavation (unit: ${ }^{\circ} \mathrm{C}$ ). 


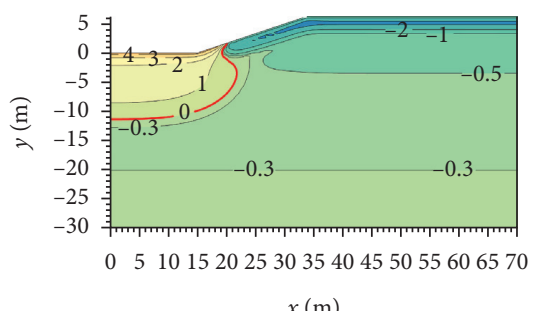

(a)

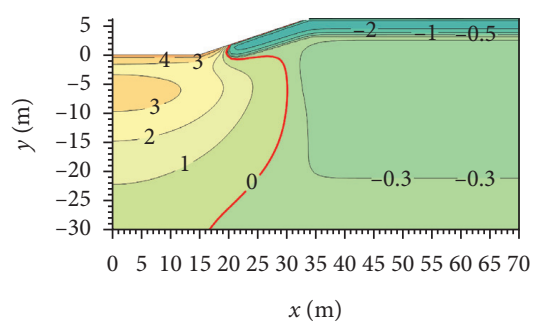

(d)

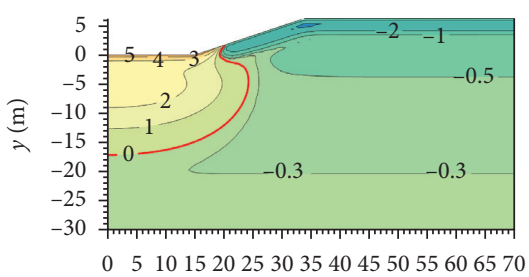

$x(\mathrm{~m})$

(b)

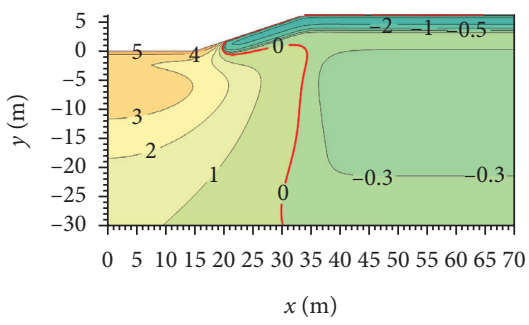

(e)

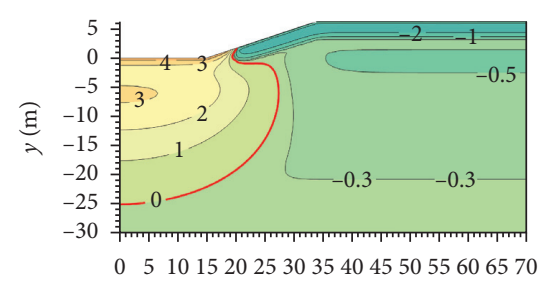

$x(\mathrm{~m})$

(c)

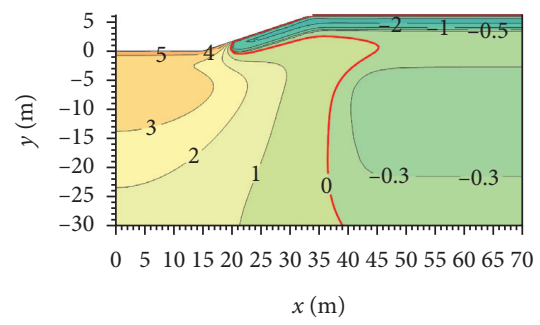

(f)

Figure 5: Thermal regimes of subgrade beneath the channel on April 15, after 5 (a), 10 (b), 20 (c), 30 (d), 40 (e), and 50 (f) years of the channel excavation (unit: ${ }^{\circ} \mathrm{C}$ ).

bottom of the channel and the water body within the channel. With the time went on, the thaw bulb developed rapidly both in vertical and lateral directions. Special attention should be paid to ground thermal regimes beneath the slope of the channel. The shallow ground on the slope was frozen but the deep ground was thawed in the cold season due to the lateral thermal erosion of the flowing water. Till the $50^{\text {th }}$ year, the thaw bulb in the cold season reached to the natural ground about $10 \mathrm{~m}$ far away from the slope shoulder of the channel. This meant that, all the deep ground beneath the slope of the channel was thawed throughout the year.

5.3. Impacts of Channel Width on Long-Term Thermal Regimes of Permafrost Subgrade. The width of the channel is not only related to the slope stability of the channel but also the permafrost degradation beneath the channel. To investigate the impacts of the channel width, a series of numerical simulations with different widths of the channel $(15,25$, and $35 \mathrm{~m}$ ) were carried out in this study. The flow of water was determined as a constant, and then the water depths were different for the channels with different widths. With the channel widths of 15,25 , and $35 \mathrm{~m}$, the water depths were set as $1.53,1.0$, and $0.74 \mathrm{~m}$, respectively.

Figure 6 shows ground temperature profiles at CC, ST, mid-slope (MS), and SS of the channels with the widths of 15,25 , and $35 \mathrm{~m}$ on October 15 in the $15^{\text {th }}$ year after the channel excavation. It can be seen that, with different widths of the channel, the long-term thermal regimes of the subgrade differed, but the magnitudes of the difference were different at the four locations. At CC (Figure 6(a)), the ground thermal regimes for the channels with different widths were close to each other. The difference in the maximum thaw depths for the three cases was about $1 \mathrm{~m}$. This means that, with different widths, the thermal erosion from the channels did not differed considerably at this location. While, at ST, the maximum thaw depths for the channels with different widths differed considerably. The smaller the width of the channel was, the grater the maximum thaw depth was at ST (Figure 6(b)). This considerable difference was related to different water depths within the channels with different widths. When the width of the channel increased from 15 to $35 \mathrm{~m}$, the maximum thaw depth at ST decreased from 18.2 to $15.5 \mathrm{~m}$. At MS (Figure 6(c)), the difference in maximum thaw depths for the three cases was also considerable. The wider the channel was, the smaller the maximum thaw depths were. At SS (Figure 6(d)), the ground thermal regimes were also very close to each other with three widths of the channel.

The above results showed that the thermal regimes of subgrade differed considerably for the channels with different widths. The difference mainly existed at slope toe and middle of the slope. While at the centerline and slope shoulder, the ground thermal regimes were very close to each other. For slope stability, the greater thaw depth is 


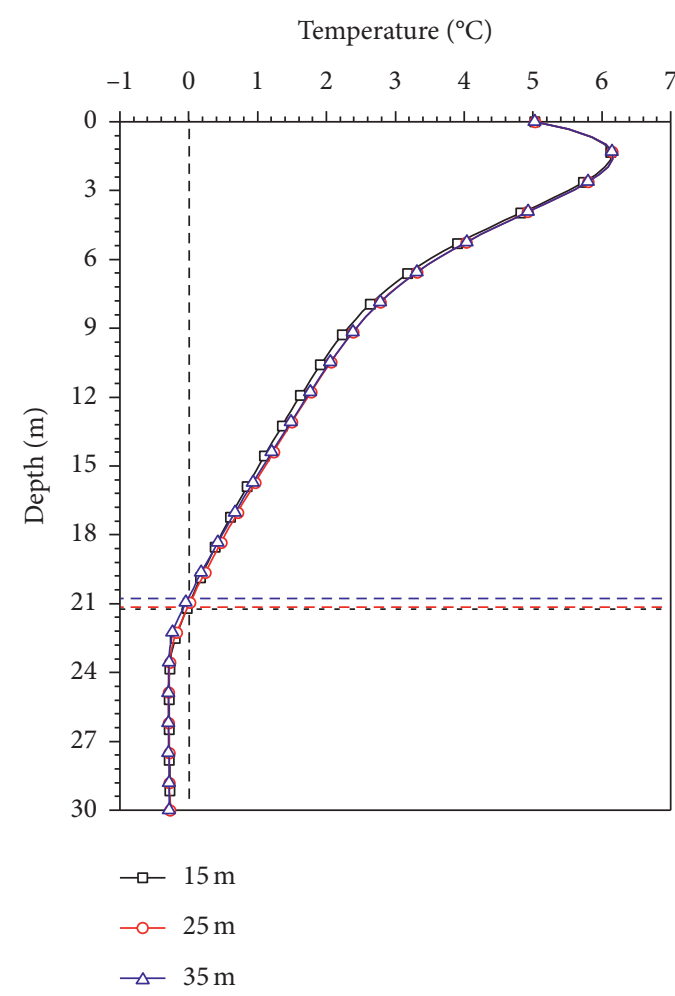

(a)

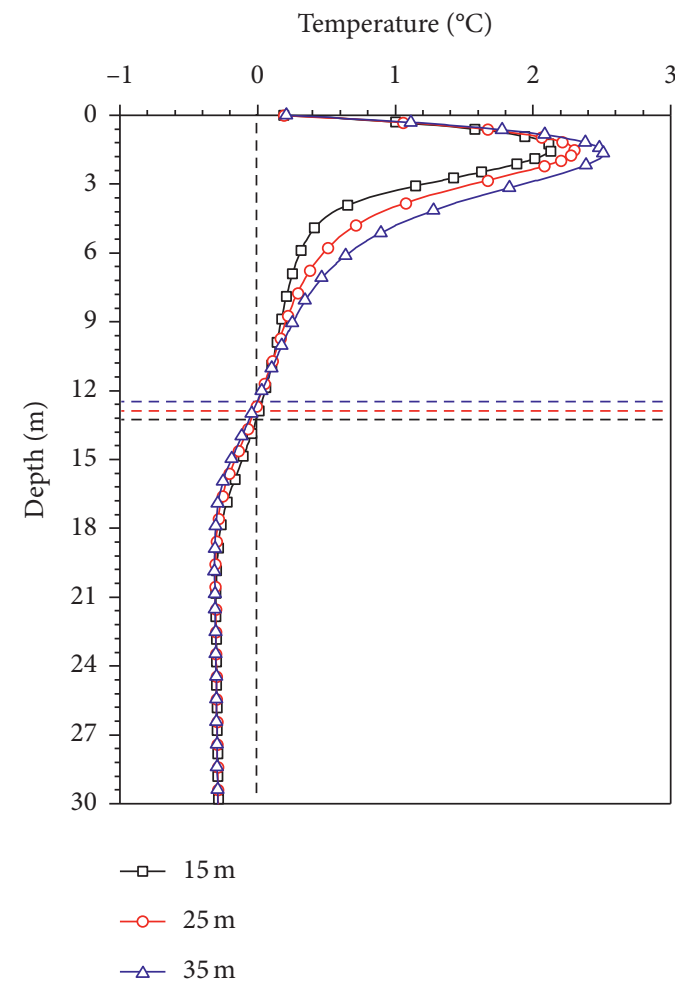

(c)

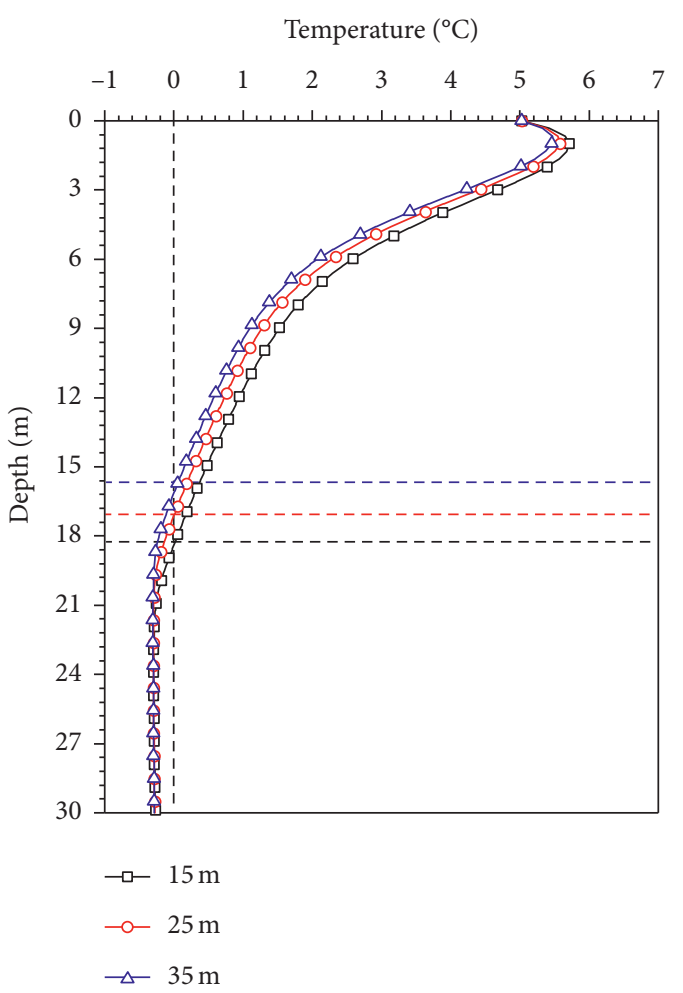

(b)

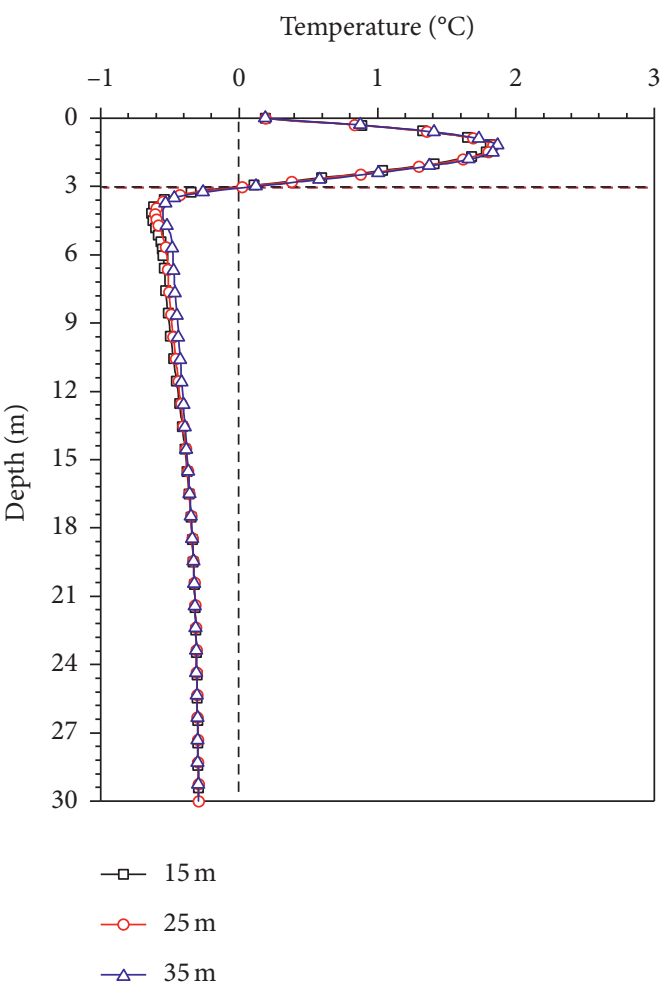

(d)

FIgUre 6: Ground temperature profiles at CC (a), ST (b), MS (c), and SS (d) of the channels with widths of 15, 25, and 35 m on October 15 in the $10^{\text {th }}$ year after the channel excavation. 
generally harmful. Thus, it can be concluded that a channel built on permafrost should be wide-and-shallow rather than narrow-and-deep if conditions permit.

\section{Conclusions}

In permafrost regions, construction of a channel involves a large amount of excavation activities and changes to surface water body, which can exert great impacts on thermal regimes of underlying permafrost. In this paper, a coupled mathematical model of heat and moisture transfer for freeze-thaw soil was constructed to investigate the long-term thermal regimes of subgrade beneath a drainage channel built for an expanding lake on the Qinghai-Tibet Plateau. Using numerical simulations, thermal regimes of the subgrade both in warm and cold seasons were analyzed during a 50 -year period, as well as the impact of the channel width. The conclusions were obtained as follows:

(1) In permafrost environment, excavation of the channel and the flowing water within could lead to a significant permafrost degradation. During the first 30 years of the channel operation, the permafrost beneath the channel mainly experienced a rapid downward degradation due to the thermal effect of the flowing water. After that, the lateral thermal erosion of the flowing water caused a rapid permafrost degradation beneath the slope of the channel. With a width of $15 \mathrm{~m}$, the permafrost beneath the channel bottom and slope would degrade totally within a depth of $30 \mathrm{~m}$ in a 50 -year period.

(2) The ground beneath the channel would not refreeze in cold seasons due to the flowing water within the channel, and the thaw bulb developed throughout a year. During the first 10 years, the thaw bulb mainly existed vertically beneath the channel. After that, the thaw bulb expanded quickly in lateral direction. Till the 50th year after the excavation of the channel, the thaw bulb reached to the natural ground about $25 \sim 30 \mathrm{~m}$ far away from the centerline of the channel with a width of $15 \mathrm{~m}$.

(3) In permafrost environment, the width of the channel is an important factor. With different widths, the long-term thermal regimes of the subgrade beneath the channels differed considerably. The maximum difference was at the slope toe of the channel. The narrower the channel was, the larger the maximum thaw depth was at the slope toe. Thus, it is recommended that the channels in permafrost environment should be designed as wide-and-shallow rather than narrow-and-deep if conditions permit.

\section{Data Availability}

The data used to support the findings of this study are available from the corresponding author upon request.

\section{Conflicts of Interest}

The authors declare that they have no conflicts of interest related to this manuscript.

\section{Acknowledgments}

This work was supported by the National Natural Science Foundation of China (nos. 41772325 and 41630636).

\section{References}

[1] S. Kozarski, L. Marks, and J. Repelewska-Pkalowa, "Multilanguage glossary of permafrost and related ground-ice terms," 1998.

[2] Y. H. Mu, G. Y. Li, W. Ma, Z. M. Song, Z. W. Zhou, and W. Fei, "Rapid permafrost thaw induced by heat loss from a buried warm-oil pipeline and a new mitigation measure combining seasonal air-cooled embankment and pipe insulation," Energy, vol. 203, Article ID 117919, 2020.

[3] S. Gruber, "Derivation and analysis of a high-resolution estimate of global permafrost zonation," The Cryosphere, vol. 5, no. 1, pp. 1547-1582, 2011.

[4] W. Dobinski, "Permafrost," Earth-Science Reviews, vol. 108, no. 3-4, pp. 158-169, 2011.

[5] P. Lu, J. Han, Z. Li et al., "Lake outburst accelerated permafrost degradation on Qinghai-Tibet Plateau," Remote Sensing of Environment, vol. 249, Article ID 112011, 2020.

[6] H. J. Jun, S. X. Li, G. D. Cheng, S. L. Wang, and X. Li, "Permafrost and climatic change in China," Global and Planetary Change, vol. 26, no. 4, pp. 387-404, 2000.

[7] H. J. Jun, Q. H. Yu, S. L. Wang, and L. Z. Lue, "Changes in permafrost environments along the Qinghai-Tibet engilneering corridor induced by anthropogenic activities and climate warming," Cold Regions Science and Technology, vol. 53, no. 3, pp. 317-333, 2006.

[8] W. Ma, G. D. Cheng, and Q. B. Wu, "Construction on permafrost foundations: lessons learned from the QinghaiTibet Railroad," Cold Regions Science and Technology, vol. 59, pp. 3-11, 2009.

[9] B. Liang, S. Qi, Z. Y. Li, Y. T. Li, and J. H. Chen, "Dynamic change of Lake area over the Tibetan Plateau and its response to climate change," Mountain Research, vol. 36, no. 2, pp. 206-216, 2018.

[10] B. K. Liu, L. Lin, Y. E. Du et al., "Causes of the outburst of Zonag lake in Hoh Xil, Tibetan plateau, and its impact on surrounding environment," Journal of Geographical Sciences, vol. 38, no. 2, pp. 305-311, 2016.

[11] J. Du, "Change of temperature in Tibetan plateau from 1961-2000," Acta Geographica Sinica, vol. 56, no. 33, pp. 232-239, 2001.

[12] T. Niu, L. Chen, and Z. Zhou, "The characteristics of climate change over the Tibetan Plateau in the last 40 years and the detection of climatic jumps," Advances in Atmospheric Sciences, vol. 21, no. 2, pp. 193-203, 2004.

[13] Y. F. Shi, Y. P. Shen, E. Kang et al., "Recent and future climate change in northwest China," Climate Change, vol. 80, no. 3-4, pp. 379-393, 2007.

[14] Q. L. You, S. C. Kang, N. Pepin et al., "Climate warming and associated changes in atmospheric circulation in the eastern and central Tibetan Plateau from a homogenized dataset," Global and Planetary Change, vol. 72, no. 1-2, pp. 11-24, 2010.

[15] G. Q. Zhang, T. D. Yao, H. J. Xie et al., "Response of Tibetan Plateau lakes to climate change: trends, patterns, and 
mechanisms," Earth-Science Reviews, vol. 208, Article ID 103269, 2020.

[16] L. Y. Tang, X. F. Duan, F. J. Kong et al., "Influences of climate change on area variation of Qinghai lake on Qinghai-Tibetan plateau since 1980s," Scientific Reports, vol. 8, no. 1, p. 7331, 2018.

[17] W. H. Liu, C. W. Xie, L. Zhao et al., "Rapid expansion of lakes in the endorheic basin on the Qinghai-Tibet Plateau since 2000 and its potential drivers," CATENA, vol. 197, Article ID 104924, 2021.

[18] G. Zhang, T. Yao, W. Chen et al., "Regional differences of lake evolution across China during 1960s-2015 and its natural and anthropogenic causes," Remote Sensing of Environment, vol. 221, pp. 386-404, 2019.

[19] C. Song, B. Huang, K. Richards, L. Ke, and V. Hien Phan, "Accelerated lake expansion on the Tibetan Plateau in the 2000s: induced by glacial melting or other processes?" Water Resources Research, vol. 50, no. 4, pp. 3170-3186, 2014.

[20] Y. Lei, K. Yang, B. Wang et al., "Response of inland lake dynamics over the Tibetan Plateau to climate change," Climatic Change, vol. 125, no. 2, pp. 281-290, 2014.

[21] W.-h. Liu, C.-w. Xie, L. Zhao et al., "Dynamic changes in lakes in the Hoh Xil region before and after the 2011 outburst of Zonag lake," Journal of Mountain Science, vol. 16, no. 5, pp. 1098-1110, 2019.

[22] Y. E. Du, B. K. Liu, W. G. He, S. Q. Duan, F. J. Hou, and Z. L. Wang, "Dynamic change and cause analysis of salt lake area in Hoh Xil on Qinghai-Tibet Plateau during 1976-2017," Journal of Geographical Sciences, vol. 40, no. 1, pp. 47-54, 2018.

[23] Q. B. Wu, Y. W. Zhou, and C. J. Tong, Permafrost Survey and Mapping, Science Press, Beijing, China, 2018.

[24] Q. Chen, D. P. Wen, X. F. Wen, and S. P. Xie, "Preliminary conception of hydrological monitoring scheme for cocoacili salt lake in Qinghai province," Yellow River, vol. 41, no. 11, pp. 7-10, 2019.

[25] X. Yao, M. Sun, P. Gong et al., "Overflow probability of the salt lake in Hoh Xil region," Journal of Geographical Sciences, vol. 28, no. 5, pp. 647-655, 2018.

[26] Y. B. Lang, Y. Zheng, W. Jin, Y. H. Mu, and M. T. Chai, "Method of three-dimensional monitoring on permafrost around lake draining project on the Qinghai-Tibet Plateau," Journal of Yangtze River Scientific Research Institute, pp. 1-8, 2020.

[27] X. J. Yao, M. P. Sun, P. Gong et al., "Overflow probability of the salt lake in Hoh Xil region," Journal of Geographical Sciences, vol. 71, no. 9, pp. 1520-1527, 2016.

[28] C. W. Xie, W. H. Liu, J. C. Wu et al., "Environmental changes caused by the outburst of Zonag Lake and the possible outburst model of Yanhu Lake in the Hoh Xil region," Journal of Glaciology and Geocryology, vol. 41, no. 6, pp. 1-16, 2019.

[29] R. H. Ma, G. S. Yang, H. T. Duan et al., "Number, area, and spatial distribution of lakes in China," Scientia Sinica (Terrae), vol. 41, no. 3, pp. 394-401, 2011.

[30] Y. H. Mu, W. Ma, Y. Z. Liu, and Z. Z. Sun, "Monitoring investigation on thermal stability of air-convection crushedrock embankment," Cold Regions Science and Technology, vol. 62, no. 2-3, pp. 160-172, 2010.

[31] Y. Mu, G. Wang, Q. Yu, G. Li, W. Ma, and S. Zhao, “Thermal performance of a combined cooling method of thermosyphons and insulation boards for tower foundation soils along the Qinghai-Tibet power transmission line," Cold Regions Science and Technology, vol. 121, pp. 226-236, 2016.
[32] Y. Mu, G. Li, Q. Yu, W. Ma, D. Wang, and F. Wang, "Numerical study of long-term cooling effects of thermosyphons around tower footings in permafrost regions along the Qinghai-Tibet power transmission line," Cold Regions Science and Technology, vol. 121, pp. 237-249, 2016.

[33] Y. Mu, W. Ma, G. Li, F. Niu, Y. Liu, and Y. Mao, "Impacts of supra-permafrost water ponding and drainage on a railway embankment in continuous permafrost zone, the interior of the Qinghai-Tibet Plateau," Cold Regions Science and Technology, vol. 154, pp. 23-31, 2018.

[34] Z. W. Wu, Y. M. Lai, and E. M. Zang, Tunnel Engineering in Cold Region, Ocean Press, Beijing, China, 2003.

[35] Y. M. Lai, M. Y. Zhang, and S. Y. Li, Theory and Application of Cold Regions Engineering, Science Press, Beijing, China, 2009.

[36] X. T. Xu, R. Q. Bai, Y. Lai, M. Y. Zhang, and J. G. Run, "Work conjugate stress and strain variables for unsaturated frozen soils," Journal of Hydrology, vol. 582, Article ID 124537, 2020.

[37] X. T. Xu, B. X. Wang, C. X. Fan, and W. D. Zhang, "Strength and deformation characteristics of silty clay under frozen and unfrozen states," Cold Regions Science and Technology, vol. 172, Article ID 102982, 2020.

[38] X. T. Xu, W. D. Zhang, C. X. Fan, Y. Lai, and J. Wu, "Effect of freeze-thaw cycles on the accumulative deformation of frozen clay under cyclic loading conditions: experimental evidence and theoretical model," Road Materials and Pavement Design, vol. 11, 2019.

[39] J. R. Mackay and C. R. Burn, “The first 20 years (1978-1979 to 1998-1999) of ice-wedge growth at the Illisarvik experimental drained lake site, western Arctic coast, Canada," Canadian Journal of Earth Sciences, vol. 39, no. 1, pp. 95-111, 2002.

[40] Z. J. Lin, F. J. Niu, J. Luo, M. H. Liu, and G. A. Yin, “Thermal regime at bottom of Thermokarst Lake along Qinghai-Tibet engineering corridor," Earth Science-Journal of China University of Geosciences, vol. 40, no. 1, pp. 179-188, 2015.

[41] F. J. Niu, Z. J. Lin, H. Liu, and J. H. Lu, "Characteristics of thermokarst lakes and their influence on permafrost in Qinghai-Tibet Plateau," Geomorphology, vol. 132, no. 3-4, pp. 222-233, 2011.

[42] Z. Wen, Z. Yang, Q. Yu et al., "Modeling thermokarst lake expansion on the Qinghai-Tibetan Plateau and its thermal effects by the moving mesh method," Cold Regions Science and Technology, vol. 121, pp. 84-92, 2016.

[43] F. Ling and T. Zhang, "Simulating heat source effect of a thermokarst lake in the first 540 years on the Alaskan Arctic using a simple lake expanding model," Cold Regions Science and Technology, vol. 160, pp. 176-183, 2019.

[44] S. Li, H. Zhan, Y. Lai, Z. Sun, and W. Pei, "The coupled moisture-heat process of permafrost around a thermokarst pond in Qinghai-Tibet Plateau under global warming," Journal of Geophysical Research: Earth Surface, vol. 119, no. 4, pp. 836-853, 2014.

[45] S. Y. Li, Y. M. Lai, M. Y. Zhang, W. S. Pei, C. Zhang, and F. Yu, "Centrifuge and numerical modeling of the frost heave mechanism of a cold-region canal," Acta Geotechnica, vol. 14, no. 12, pp. 1113-1128, 2018.

[46] H. Zhang, J. Zhang, E. Wang, Z. Zhang, W. Cao, and P. Zhou, "Thermal and settlement analyses under a riverbank over permafrost," Computers and Geotechnics, vol. 91, pp. 48-57, 2017.

[47] H. Zhang, J. Zhang, E. Wang, M. Zhang, Z. Zhang, and M. Chai, "Analysis of thermal regime under riverbank in permafrost region," Applied Thermal Engineering, vol. 123, pp. 963-972, 2017. 
[48] R. L. Harlan, "Analysis of coupled heat-fluid transport in partially frozen soil," Water Resources Research, vol. 9, no. 5, pp. 1314-1323, 1973.

[49] X. Z. Xu, J. C. Wang, and L. X. Zhang, Physics of Frozen Soil, Science Press, Beijing, China, 2010.

[50] M. L. Zhang, Z. Wen, K. Xue, L. Z. Chen, and D. S. Li, “A coupled model for liquid water, water vapor and heat transport of saturated-unsaturated soil in cold regions: model formulation and verification," Environmental Earth Sciences, vol. 75, no. 8, pp. 1-19, 2016.

[51] K. Hansson, J. Simunek, M. Mizoguchi, L.-C. Lundin, and M. T. van Genuchten, "Water flow and heat transport in frozen soil: numerical solution and freeze-thaw applications," Vadose Zone Journal, vol. 3, no. 2, pp. 693-704, 2004.

[52] M. L. Zhang, "The influence of rainfall variations on the thermal-moisture dynamics of the embankment in permafrost regions of the Qinghai-Tibet Plateau," Ph. D. dissertation, University of Chinese Academy of Sciences, Lanzhou, China, 2016.

[53] M. T. van Genuchten, "A closed-form equation for predicting the hydraulic conductivity of unsaturated soils," Soil Science Society of America Journal, vol. 44, no. 5, pp. 892-898, 1980.

[54] Y. Mualem, "A new model for predicting the hydraulic conductivity of unsaturated porous media," Water Resources Research, vol. 12, no. 3, pp. 513-522, 1976.

[55] Y.-W. Jame and D. I. Norum, "Heat and mass transfer in a freezing unsaturated porous medium," Water Resources Research, vol. 16, no. 4, pp. 811-819, 1980.

[56] W. D. An, Z. W. Wu, and W. Ma, Interaction Among Temperature, Moisture and Stress Field in Frozen Soil, Lanzhou University Press, Lanzhou, China, 1990.

[57] W. D. An, Z. W. Wu, and W. Ma, Temperature, Water Stress and Interaction of Frozen Soil, Lanzhou University press, Lanzhou, China, 1989.

[58] Y. M. Lai, Z. W. Wu, S. J. Zhang, W. B. Yu, and Y. S. Deng, "In-situ observed study for effect of heat preservation in cold regions tunnels," Journal of the China Railway Society, vol. 1, pp. 81-86, 2003.

[59] H. B. Dillon and O. B. Andersland, "Predicting unfrozen water contents in frozen soils," Canadian Geotechnical Journal, vol. 3, no. 2, pp. 53-60, 1966.

[60] D. M. Anderson and N. R. Morgenstern, "Physics, chemistry, and mechanics of frozen ground: a review," in Proceedings of the Second International Conference on Permafrost, pp. 257288, National Academy of Sciences, Washington, DC, USA, July 1973.

[61] L. U. Arenson and D. C. Sego, "The effect of salinity on the freezing of coarse-grained sands," Canadian Geotechnical Journal, vol. 43, no. 3, pp. 325-337, 2006.

[62] M. M. Darrow, S. L. Huang, and S. Akagawa, "Adsorbed cation effects on the frost susceptibility of natural soils," Cold Regions Science and Technology, vol. 55, no. 3, pp. 263-277, 2009.

[63] H. P. Hu, S. X. Yang, and Z. D. Lei, "A numerical simulation for heat and moisture transfer during soil freezing," Journal of Hydraulic Engineering, vol. 7, pp. 1-8, 1992.

[64] Y. X. Xia and Y. D. Wang, Mechanical Calculation of Tunnel Structure, People's Communications Press, Beijing, China, 2001.

[65] J. M. Zhang, "Study on roadbed stability in permafrost regions on Qinghai-Tibetan plateau and classification of permafrost in Highway engineering," Ph. D. Dissertation, University of Chinese Academy of Sciences, Lanzhou, China, 2004.
[66] T. R. Erickson and H. G. Stefan, "Linear air/water temperature correlations for streams during open water periods," Journal of Hydrologic Engineering, vol. 5, no. 3, pp. 317-321, 2000. 